\title{
Etiologia, perfil de sensibilidade aos antimicrobianos e aspectos epidemiológicos na otite canina: estudo retrospectivo de 616 casos
}

\section{Etiology, antimicrobial susceptibility profile and epidemiological aspects in canine otitis: a retrospective study of 616 cases}

\author{
Verônica Baldim de Oliveira ${ }^{1}$; Márcio Garcia Ribeiro ${ }^{2 *}$; \\ Ariani Cristina da Silva Almeida ${ }^{1}$; Antônio Carlos Paes $^{2}$; Larissa Anuska Zeni \\ Condas $^{3}$; Gustavo Henrique Batista Lara ${ }^{3}$; Marília Masello Junqueira Franco 3 ; \\ Marta Catarina Fernandes ${ }^{3}$; Fernando José Paganini Listoni ${ }^{4}$
}

\section{Resumo}

\begin{abstract}
Estudo retrospectivo da etiologia, perfil de sensibilidade microbiana, ocorrência de multirresistência dos isolados e os principais aspectos epidemiológicos foram investigados em 616 casos de otite canina. Staphylococcus $\beta$ hemolítico (26,27\%), Malassezia pachydermatis (12,35\%) e Pseudomonas aeruginosa $(8,8 \%)$ foram os micro-organismos mais frequentes. Os isolados foram sensíveis "in vitro" principalmente a norfloxacina $(89,62 \%)$, gentamicina $(83,25 \%)$ e ofloxacina $(80,16 \%)$. Alta ocorrência de resistência das linhagens foi observada frente à neomicina $(30,84 \%)$ e cefalexina $(27,63 \%)$. A ocorrência de resistência múltipla a três ou mais e cinco ou mais dos antimicrobianos foi observada em, respectivamente, $34,9 \%$ e $15,5 \%$ dos isolados. Os casos ocorreram predominantemente nos primeiros anos de idade, em animais sem raça definida, no período do outono. A presença de prurido, mau cheiro e secreção no conduto auditivo foram os principais sinais observados ao exame clínico.

Palavras-chave: Otite, cão, etiologia, sensibilidade microbiana "in vitro", epidemiologia
\end{abstract}

\begin{abstract}
A retrospective study of etiology, antimicrobial susceptibility profile and multiple drug resistance, and major epidemiological aspects were investigated in 616 cases of canine otitis. Staphylococcus $\beta$ hemolitic (26.27\%), Malassezia pachydermatis (12.35\%), and Pseudomonas aeruginosa (8.8\%) were the most common microorganisms identified. The isolates were susceptible mainly to norfloxacin $(89.62 \%)$, gentamicin $(83.25 \%)$, and ofloxacin $(80.16 \%)$. High occurrence of resistance of isolates was observed to neomicin $(30.84 \%)$ and cephalexin $(27.63 \%)$. Multiple drug resistance to three or more and five or more of antimicrobials tested was observed in $34.9 \%$ and $15.5 \%$ of isolates, respectively. The cases of canine otitis occurred predominantly in first years of age, in mixed breeds animals, at autumn season. The presence of itch, bad smell, and secretion in ear conduct were the major signs observed at clinical examination.
\end{abstract}

Key words: Otitis, dog, etiology, antimicrobial susceptibility, epidemiology

${ }^{1}$ Residente em Enfermidades Infecciosas dos Animais, Dept ${ }^{\circ}$ de Higiene Veterinária e Saúde Pública, DHVSP, Faculdade de Medicina Veterinária e Zootecnia, FMVZ/ UNESP, Botucatu, SP. E-mail: veronicabaldim@hotmail.com; arianicristina@yahoo. com.br

2 Profs. Adjuntos, Enfermidades Infecciosas dos Animais,DHVSP, FMVZ/UNESP, Botucatu, SP. E-mail: mgribeiro@fmvz.unesp. br; paesacmi@fmvz.unesp.br

3 Pós-graduando(s) em Saúde Animal, Saúde Pública Veterinária e Segurança Alimentar, SASPVSA, FMVZ/UNESP, Botucatu, SP.E-mail: anuskavet@gmail.com; gunnys7@gmail.com; marilia_gu@uol.com.br; marta@fmvz.unesp.br

4 Técnico do Laboratório de Diagnóstico Microbiológico, DHVSP, FMVZ/UNESP, Botucatu, SP. E-mail: fernando.listoni@fmvz. unesp.br

* Autor de correspondência 


\section{Introdução}

A otite canina figura dentre as infecções mais frequentes em cães, acometendo 15 a $20 \%$ dos animais, em qualquer faixa etária. Esta afecção é dividida classicamente em otite externa, média e interna, segundo a localização e gravidade do processo inflamatório no conduto auditivo (GOTTHELF, 2007; NELSON; COUTO, 2010).

A doença possui etiologia multifatorial envolvendo causas primárias, predisponentes ou perpetuantes. As causas primárias são representadas por dermatopatias do revestimento epitelial do conduto auditivo, a exemplo da atopia, parasitas e disqueratoses. Os fatores predisponentes correspondem a alterações anatômicas e fisiológicas do canal auditivo, como excesso de dobras cutâneas, orelhas pendulares, excesso de pelos e neoplasias. Os fatores perpetuantes incluem principalmente manipulação incorreta do conduto auditivo pelos proprietários dos cães, e a multiplicação desordenada de bactérias e leveduras no conduto e em estruturas anexas do ouvido (GOTTHELF, 2007).

Os principais sinais clínicos observados na otite canina são prurido, eritema, otalgia, meneio cefálico, escoriações auriculares secundárias ao ato de coçar, desconforto na manipulação do conduto e secreção abundante com odor fétido (SLATTER, 2007; NELSON; COUTO, 2010). Ocasionalmente, a afecção do conduto auditivo se manifesta também por sinais de vocalização, agitação e até certa hiperexcitabilidade (ETTINGER; FELDMAN, 2004; NELSON; COUTO, 2010).

O diagnóstico de rotina da otite em cães é firmado com base no exame clínico do animal e do conduto auditivo, aliado aos achados epidemiológicos, exames subsidiários citológicos, microbiológicos e de diagnóstico por imagem (ETTINGER; FELDMAN, 2004; GOTTHELF, 2007; GREENE, 2012). Os micro-organismos mais frequentemente isolados na otite canina são: Staphylococcus pseudintermedius, Staphylococcus intermedius, Staphylococcus aureus, Malassezia pachydermatis (M. pachydermatis), Pseudomonas aeruginosa (P. aeruginosa), Escherichia coli (E. coli) e os gêneros Streptococcus, Proteus e Candida (MATSUDA et al., 1984; ETTINGER; FELDMAN, 2004; GOTTHELF, 2007).

O tratamento de rotina da otite externa canina consiste na limpeza do canal auditivo aliado a terapia antimicrobiana tópica. Nos casos crônicos, ou na otite média e interna, se recomenda associar a terapia tópica à parenteral, além da abordagem cirúrgica. No entanto, o uso de antimicrobianos sem o respaldo de testes "in vitro" de sensibilidade microbiana pode reduzir a efetividade do tratamento, ou mesmo aumentar a pressão seletiva para linhagens multirresistentes aos antimicrobianos convencionais (SLATTER, 2007; NELSON; COUTO, 2010).

O presente estudo investigou retrospectivamente 616 casos de otite em cães, com ênfase na identificação etiológica, no perfil de sensibilidade dos isolados aos antimicrobianos e na avaliação dos principais achados epidemiológicos.

\section{Material e Métodos}

Durante o período compreendido entre 2003 a 2009 foram investigados casos de otite na FMVZUNESP/Botucatu, SP.

Neste estudo, foram utilizados cães com otopatias externa, média, e interna. As otopatias foram diagnosticadas pela presença de alterações clínicas no conduto identificadas durante o exame físico auxiliado pela avaliação com otoscópio. Foram considerados otopatas os cães que apresentaram dois ou mais sinais indicativos de otite externa (prurido, dor à palpação, alterações na quantidade, cor e odor da secreção auricular, estenose parcial do conduto, pontos hemorrágicos), média ou interna (hemorragias, estenose total do conduto, meneio cefálico, perda da integridade da membrana timpânica).

Foram colhidas secreções internas da região dos condutos auditivos com auxílio de suabes esterilizados, evitando no procedimento de colheita o contato com os pelos do conduto. As secreções 
foram submetidas imediatamente aos exames bacteriológico e micológico. Os espécimes foram cultivados nos meios de ágar sangue bovino (5\%) desfibrinado e ágar MacConkey, incubados em condições de aerobiose a $37^{\circ} \mathrm{C}$, mantidos por 72 horas. Simultaneamente foi realizada a cultura em meio Sabouraud, mantida sob temperatura ambiente $\left(25^{\circ} \mathrm{C}\right)$, por até 15 dias. Os microorganismos isolados foram identificados com base nas características morfotintoriais, bioquímicas e de cultivo (QUINN et. al., 1994; LACAZ et al., 1998). Foi utilizado para o estudo somente a secreção de um conduto auricular de cada animal. Desta forma, cada secreção auricular correspondeu a uma unidade animal (caso).

Todos os isolados de origem bacteriana foram submetidos ao teste de sensibilidade microbiana "in vitro", utilizando o método de difusão com discos (NCCLS, 2006), frente aos seguintes antimicrobianos: cefalexina $(30 \mu \mathrm{g})$, ciprofloxacina $(5 \mu \mathrm{g})$, enrofloxacina $(5 \mu \mathrm{g})$, gentamicina $(10 \mu \mathrm{g})$, ofloxacina $(5 \mu \mathrm{g})$, neomicina $(30 \mu \mathrm{g})$, tobramicina $(10 \mu \mathrm{g})$ e norfloxacina $(10 \mu \mathrm{g})$.

\section{Resultados}

No período compreendido do estudo foram avaliados 616 casos de otite em cães. A secreção do conduto auditivo dos animais foi encaminhada para o diagnóstico microbiológico e teste de sensibilidade microbiana "in vitro", no laboratório de Enfermidades Infecciosas dos Animais.

As principais queixas dos proprietários residiam na presença de prurido local, otalgia, presença de lesões no conduto, alterações no posicionamento do pavilhão auricular, otorréia fétida em região de pina e conduto auditivo, de localização uni ou bilateral.

Foram submetidas ao cultivo microbiológico as secreções auriculares provenientes de cães entre um mês e 16 anos, compreendidos por 347 (56,3\%) animais machos e 269 (43,7\%) fêmeas.

Foi observada alta ocorrência de otite em animais com até 10 anos de idade, apesar do declínio gradual do número de casos observado a partir do segundo ano de idade (Figura 1). Houve maior frequência de otite em cães sem raça definida seguidos das raças poodle, cocker, labrador, pastor alemão, boxer e rottweiller (Figura 2).

Em todos os espécimes clínicos foram isoladas bactérias ou leveduras, em cultura pura ou em associação. Os micro-organismos mais frequentes foram Staphylococcus $\beta$ hemolítico, $M$. pachydermatis e $P$. aeruginosa. Nos 616 casos foram isoladas 686 linhagens de micro-organismos, das quais 477 em cultura pura e 209 em associação (Tabela 1).

Figura 1. Ocorrência de otite em 616 cães segundo a faixa etária. Botucatu, SP, 2003 a 2009.

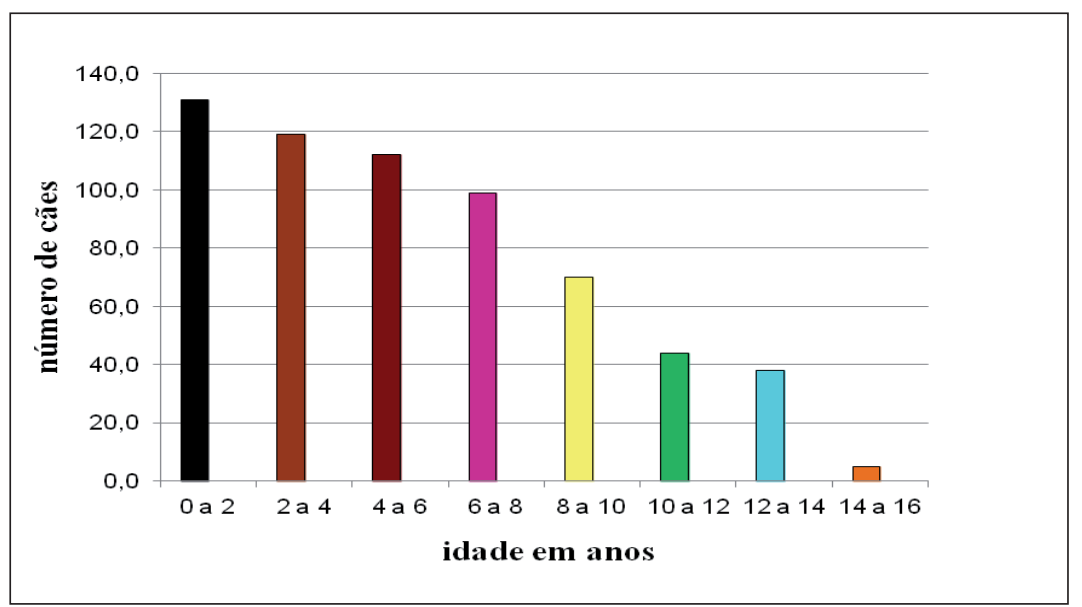

Fonte: Elaborado pelos autores. 
Figura 2. Ocorrência de otite canina em 616 cães segundo diferentes raças. Botucatu, SP, 2003 a 2009.

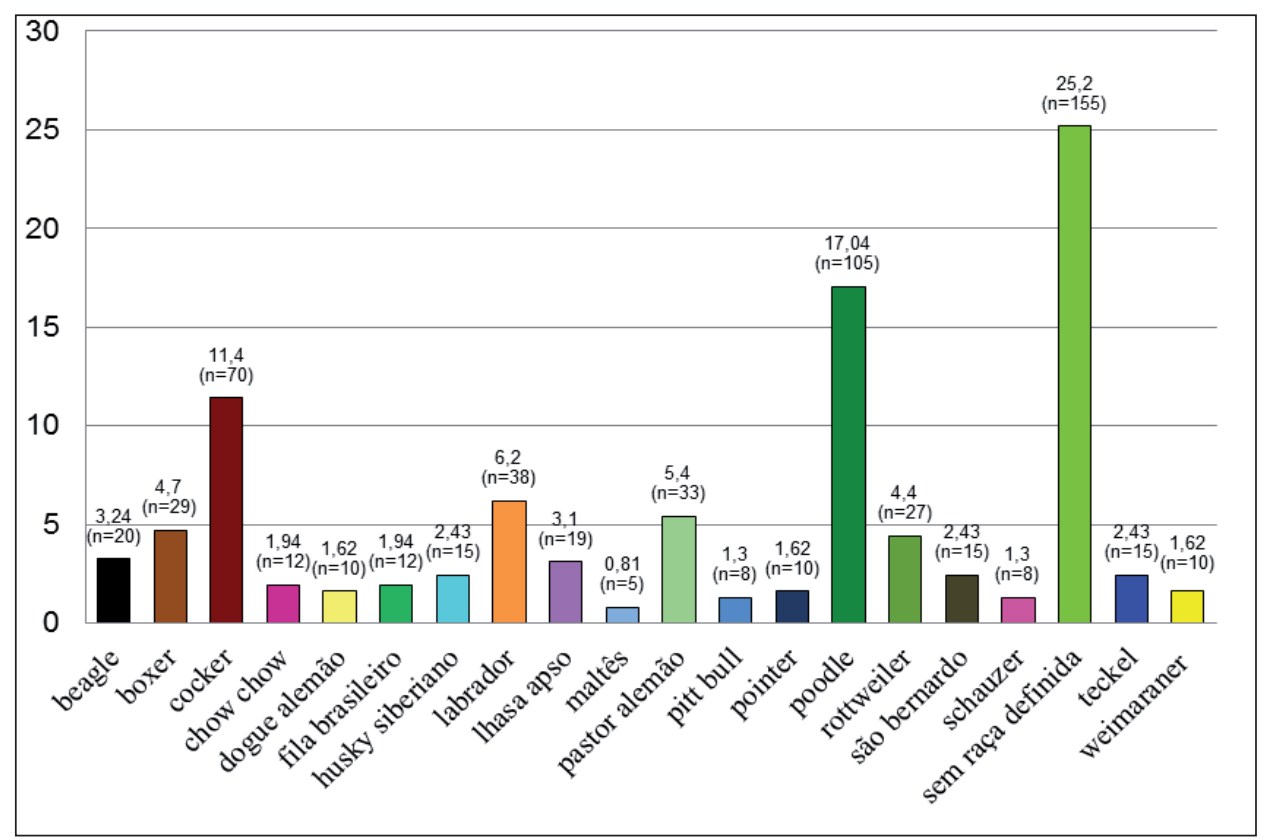

Fonte: Elaborado pelos autores.

Tabela 1. Micro-organismos isolados em 616 amostras de exsudato otológico de cães com otite. Botucatu, SP, 2003 a 2009.

\begin{tabular}{lcc}
\hline Micro-organismos & Número de Isolados & $\mathbf{\%}$ \\
\hline Staphylococcus $\beta$ hemolítico & 185 & 26,27 \\
Malassezia pachydermatis & 87 & 12,35 \\
Pseudomonas aeruginosa & 62 & 8,80 \\
Staphylococcus spp. & 30 & 4,26 \\
Proteus mirabilis & 28 & 3,97 \\
Escherichia coli & 18 & 2,55 \\
Proteus spp. & 10 & 1,42 \\
Staphylococcus $\alpha$ hemolítico & 8 & 1,13 \\
Outros isoladamente ${ }^{1}$ & 49 & 6,96 \\
\hline Sub total & 477 & 69,53 \\
\hline Staphylococcus $\beta$ hemolítico + M. pachydermatis & 44 & 6,25 \\
Staphylococcus $\beta$ hemolítico + P. aeruginosa & 20 & 2,84 \\
Streptococcus $\beta$ hemolítico + Staphylococcus $\beta$ hemolítico & 14 & 1,98 \\
Staphylococcus $\beta$ hemolítico + P. aeruginosa & 11 & 1,56 \\
Proteus mirabilis + P. aeruginosa & 9 & 1,27 \\
Streptococcus $\beta$ hemolítico + P. aeruginosa & 9 & 1,27 \\
Staphylococcus spp. + Staphylococcus $\beta$ hemolítico & 7 & 0,99 \\
Outros em associação ${ }^{2}$ & 95 & 13,49 \\
\hline Sub total & 209 & 30,47 \\
\hline Total & 686 & 100,0 \\
\hline
\end{tabular}

${ }_{1,2}$ Proteus vulgaris, Staphylococcus epidermidis, Staphylococcus intermedius, Staphylococcus pseudintermedius, Streptococcus spp., Klebsiella spp., Morganella morganii, Enterobacter cloacae, Alcaligenes faecalis, Corynebacterium spp., Microsporum canis, Staphylococcus aureus. M. pachydermatis = Malassezia pachydermatis; P. aeruginosa = Pseudomonas aeruginosa .

Fonte: Elaborado pelos autores. 
Os isolados foram sensíveis "in vitro" da neomicina $(30,84 \%)$ e cefalexina $(27,63 \%)$ principalmente para norfloxacina $(89,62 \%)$, (Tabela 2$)$. gentamicina $(83,25 \%)$, ofloxacina $(80,16 \%)$, tobramicina $(74,28 \%)$, ciprofloxacina $(73,17 \%)$ e enrofloxacina $(69,39 \%)$. Em contraste, a maior resistência das estirpes foi observada com o uso

A ocorrência de resistência múltipla a três ou mais e a cinco ou mais dos antimicrobianos utilizados foi observada em, respectivamente, $34,9 \%$ e $15,5 \%$ dos isolados.

Tabela 2. Perfil de sensibilidade microbiana "in vitro", no teste de difusão com discos, em isolados bacterianos obtidos de casos de otite canina. Botucatu, SP, 2003 a 2009.

\begin{tabular}{|c|c|c|c|c|c|c|}
\hline \multirow[b]{2}{*}{ Antimicrobianos } & \multirow{2}{*}{\multicolumn{2}{|c|}{$\begin{array}{c}\text { Sensível } \\
\mathrm{n}^{\mathrm{o}} \text { de sensíveis } \\
\mathrm{n}^{\mathrm{o}} \text { de testados }(\%) \\
\end{array}$}} & \multirow{2}{*}{\multicolumn{2}{|c|}{$\begin{array}{c}\text { Parcialmente Sensível } \\
\mathrm{n}^{\circ} \text { de } \mathrm{PS} \\
\mathrm{n}^{\mathrm{o}} \text { de testados }(\%)\end{array}$}} & \multirow{2}{*}{\multicolumn{2}{|c|}{$\begin{array}{c}\text { Resistente } \\
\mathrm{n}^{\mathrm{o}} \text { de resistentes } \\
\mathrm{n} \mathrm{o} \text { de testados (\%) }\end{array}$}} \\
\hline & & & & & & \\
\hline Cefalexina & $515 / 778$ & $(66,19 \%)$ & $48 / 778$ & $(6,16 \%)$ & $215 / 778$ & $(27,63 \%)$ \\
\hline Ciprofloxacina & $562 / 768$ & $(73,17 \%)$ & $109 / 768$ & $(14,19 \%)$ & $97 / 768$ & $(12,63 \%)$ \\
\hline Enrofloxacina & $526 / 758$ & $(69,39 \%)$ & $101 / 758$ & $(13,32 \%)$ & $131 / 758$ & $(17,28 \%)$ \\
\hline Gentamicina & $666 / 800$ & $(83,25 \%)$ & $32 / 800$ & $(4 \%)$ & $102 / 800$ & $(12,75 \%)$ \\
\hline Neomicina & $387 / 749$ & $(51,66 \%)$ & $131 / 749$ & $(17,48 \%)$ & $231 / 749$ & $(30,84 \%)$ \\
\hline Norfloxacina & $639 / 713$ & $(89,62 \%)$ & $55 / 713$ & $(7,71 \%)$ & $19 / 713$ & $(2,66 \%)$ \\
\hline Ofloxacina & $598 / 746$ & $(80,16 \%)$ & $44 / 746$ & $(5,89 \%)$ & $104 / 746$ & $(13,94 \%)$ \\
\hline Tobramicina & $548 / 738$ & $(74,28 \%)$ & $44 / 738$ & $(5,96 \%)$ & $146 / 738$ & $(19,78 \%)$ \\
\hline
\end{tabular}

PS = Parcialmente Sensível/ no = número.

Fonte: Elaborado pelos autores.

\section{Discussão}

A otite é considerada uma das afecções mais comuns na rotina de diagnóstico clínico de pequenos animais (NELSON; COUTO, 2010).

Diferentes autores têm relatado predomínio da ocorrência da otite em cães com idade igual ou superior a quatro anos (GRONO, 1969; MAGALHÃES; SILVA; MARQUES JUNIOR, 1985; CASTELLANO, 1995). Em contraste, no presente estudo foram encontrados animais com otite desde os primeiros meses de vida até 16 anos de idade, com relativo predomínio nos primeiros anos de vida, indicando que os cães são susceptíveis à otite em qualquer faixa etária.

Neste estudo, grande parte das raças acometidas por otite apresentavam a presença de orelhas pendulares e/ou excesso de pelos no interior do conduto auditivo, incluindo cães das raças poodle, cocker, labrador, pastor alemão, boxer e rottweiller.
Tal achado também foi evidenciado em estudos similares com otite canina em outros países (RYCROFT; SABEN, 1977; BABA; FUKATA, 1981; HAMMOND; CONROY; WOODY, 1990) e no Brasil (CUNHA et al., 2003). A presença deste fator anatômico pode predispor ao desequilíbrio do microambiente do conduto auditivo, favorecendo a multiplicação excessiva dos micro-organismos de origem bacteriana e fúngica, que atuam como perpetuantes do processo inflamatório nos tecidos de revestimento e estruturas associadas ao ouvido (GOTTHELF, 2007).

Houve predomínio de cães machos dentre os 616 animais com otite avaliados no presente estudo. Ao contrário, Cunha et al. (2003) também no Brasil, observaram maior frequência de fêmeas com otite, ao investigarem achados clínicos e citológicos da infecção em cães. Estes resultados indicam que o sexo dos cães provavelmente exerça pouca influência no estabelecimento da otite na espécie. 
Staphylococcus $\beta$ hemolítico, M. pachydermatis e $P$. aeruginosa foram os micro-organismos mais frequentemente identificados nos 616 cães com otite, tanto em cultura pura como associados. Estudos similares têm apontado que os estafilococos, estreptococos, M. pachydermatis, P. aeruginosa, e certas enterobactérias, como E. coli, são os principais agentes causais na ocorrência da otite em cães (COLE et al., 1998; ETTINGER; FELDMAN, 2004; GREENE, 2012).

A alta frequência de $P$. aeruginosa nos 616 cães com otite amostrados ocorreu, provavelmente, por veiculação hídrica do micro-organismo para o conduto auditivo, visto que várias afecções em animais por esta bactéria são veiculadas pela água (QUINN et al., 1994, 2005; FERNANDES et al., 2009). Os gêneros Staphylococcus e Streptococcus possuem como habitat a pele, mucosas e conjuntivas de animais, que inclui o revestimento interior do conduto auditivo dos cães (QUINN et al., 1994, 2005; NELSON; GOTTHELF, 2007; GOTTHELF, 2007; COUTO, 2010). As enterobactérias e a levedura $M$. pachydermatis geralmente são veiculadas para o interior do ouvido pela água e ambiente contaminados e possuem, em comum, boas condições de multiplicação em ambientes úmidos, como o interior do conduto auditivo (QUINN et al., 1994, 2005; LACAZ et al., 1998; GOTTHELF, 2007; GREENE, 2012). O conjunto dos fatores supracitados favorece as infecções do conduto auditivo dos cães pelos estafilococos, estreptococos, enterobactérias, $P$. aeruginosa e M. pachydermatis, e reforça o predomínio destes micro-organismos nos casos de otite em cães.

Os isolados de origem bacteriana identificados no presente estudo apresentaram maior sensibilidade "in vitro" frente a norfloxacina, ofloxacina, ciprofloxacina e enrofloxacina. Estes fármacos pertencem ao grupo das fluorquinolonas e foram idealizados originalmente (1 $\stackrel{\text { a }}{\text { geração) }}$ como antimicrobianos de escolha para bactérias gramnegativas, incluindo $P$. aeruginosa e enterobactérias. As gerações subsequentes das fluorquinolonas (2 e $3^{\mathrm{a}}$ gerações) apresentam espectro extendido para micro-organismos gram-positivos, particularmente do gênero Staphylococcus (TAVARES, 2001). No presente estudo, a boa efetividade "in vitro" deste grupo de fármacos frente aos isolados obtidos dos casos de otite pode ser creditada ao uso ainda moderado das fluorquinolonas em medicina veterinária e do amplo espectro de ação - notadamente para $P$. aeruginosa intimamente relacionado a casos crônicos de otite canina (HARIHARAN et al., 2006) -, se constituindo em antimicrobianos de eleição na terapia de afecções do conduto auditivo em cães.

A semelhança das fluorquinolonas, os isolados bacterianos apresentaram alta sensibilidade, a gentamicina e tobramicina. $\mathrm{O}$ bom espectro de efetividade destes aminoglicosídeos, particularmente para micro-organismos gramnegativos e certos cocos gram positivos como os estafilococos (TAVARES, 2001), somado a apresentação comercial que possibilita o tratamento tópico, se constituem em fatores que favorecem a indicação destes fármacos na terapia da otite em cães.

Em contraste, os maiores índices de resistência dos isolados foram constatados nos cães do presente estudo com o uso de cefalexina e neomicina. A baixa efetividade destes fármacos pode ser justificada, em parte, pela produção de $\beta$-lactamases por linhagens de Staphylococcus spp., enterobactérias e Pseudomonas aeruginosa (SHIMIZU et al., 2001; TAVARES, 2001), e o uso há décadas da neomicina no tratamento tópico da otite canina. Apesar da preocupação emergente com a resistência múltipla de bactérias aos antimicrobianos convencionais de uso veterinário (TAVARES, 2001; ANDRADE, 2008), poucos estudos no Brasil tem sido conduzidos com intuito de investigar a presença de linhagens multirresistentes isoladas de otite canina. Oliveira et al. (2006) descreveram resistência múltipla a dois ou mais antimicrobianos em 35,2\% das linhagens de Staphylococcus intermedius isoladas de casos de otite no Brasil, notadamente frente as penicilinas e 
derivados (penicilina $\mathrm{G}$ e ampicilina), macrolídeos (clindamicina e eritromicina) e tetraciclinas. Souza et al. (2006) relataram a ocorrência de multirresistência aos antimicrobianos em 135 linhagens de Pseudomonas aeruginosa isoladas de casos de otite canina.

A complexidade de micro-organismos de origem bacteriana e a ocorrência de multirresistência das linhagens aos antimicrobianos observado no presente estudo, notadamente aos fármacos convencionais como neomicina e cefalexina, reforça a necessidade do uso racional dos antibióticos e quimioterápicos na prática terapêutica em medicina veterinária e do tratamento dos casos de otite com o respaldo de testes "in vitro" de sensibilidade aos antimicrobianos, com intuito de incrementar as taxas de efetividade no tratamento dessa afecção em cães.

\section{Conclusão}

A otite é uma das afecções mais comuns na clínica médica de pequenos animais. A etiologia é complexa, predominante bacteriana. O diagnóstico é fundamentado no exame clínico do animal, do conduto auditivo, aliado aos achados epidemiológicos, exames subsidiários como citologia, cultivo microbiano e antibiograma. O diagnóstico da etiologia primária e o tratamento com respaldo em testes de sensibilidade microbiana "in vitro" são fundamentais para elevar as taxas de cura. A educação do proprietário e noções sobre posse responsável dos animais, aliado a outras medidas como a limpeza, a retirada do excesso de pelos e da umidade do conduto auditivo são imprescindíveis na profilaxia/controle da otite em cães.

\section{Referências}

ANDRADE, S. F. Manual de terapêutica veterinária. 3. ed. São Paulo: Roca, 2008. 720 p.

BABA, E.; FUKATA, T. Incidence of otitis externa in dogs and cats in Japan. Veterinary Record, Londres, v. 108, n. 18, p. 393-395, 1981.
CASTELLANO, M. J. Evaluacion clínica del perro con otitis externa. Veterinaria Argentina, Buenos Aires, v. 12, p. 332-337, 1995.

COLE, L. K.; KWOCHKA, K. W.; KOWALSKI, J. J.; HILLIER, A. Microbial flora and antimicrobial susceptibility patterns of isolated pathogens from the horizontal ear canal and middle ear in dogs with otitis media. Journal of the American Veterinary Medical Association, Schaumburg, v. 212, n. 4, p. 534-538, 1998.

CUNHA, F. M.; COUTINHO, S. D.; MATERA, A.; FIORIO, W. A. B.; RAMOS, M. C.; SILVEIRA, L. M. G. Avaliação clínica e citológica do conduto auditivo externo de cães com otite. Revista Educação Continuada $C R M V$-SP, São Paulo, v. 6, n. 1-3, p. 7-15, 2003.

ETTINGER, J. S.; FELDMAN, C. E. Tratado de medicina interna veterinária. 5. ed. Rio de Janeiro: Guanabara Koogan, 2004. 2156 p. 2 v.

FERNANDES, M. C.; RIBEIRO, M. G.; SIQUEIRA, A. K.; SALERNO, T.; LARA, G. H. B.; LISTONI, F. J. P. Surto de mastite bovina causada por linhagens de Pseudomonas aeruginosa multi-resistentes aos antimicrobianos. Arquivo Brasileiro de Medicina Veterinária e Zootecnia, Belo Horizonte, v. 61, n. 3, p. 745-748, 2009.

GOTTHELF, G. N. Doenças do ouvido em pequenos animais. 2. ed. São Paulo: Roca, 2007. 356 p.

GREENE, C. E. Infectious diseases of the dog and cat. 4. ed. St. Louis, Missouri: Elsevier, 2012. 1357 p.

GRONO, L. R. Observations on the incidence of otitis externa in the dog. Australian Veterinary Journal, Milton, v. 45, p. 417-419, 1969.

HAMMOND, D. L.; CONROY, J. D.; WOODY, B. L. Histological effects of a chemical depilatory on the auditory canal of dogs. Journal of Small Animal Hospital Association, Denver, v. 26, n. 5, p. 551-554, 1990.

HARIHARAN, H.; COLES, M.; POOLE, M.; LUND, L.; PAGE, R. Update on antimicrobial susceptilites of bacterial from canine and feline otitis externa. Canadian Veterinary Journal, Ottawa, v. 47, n. 3, p. 253-255, 2006.

LACAZ, C. S.; PORTO, E.; VACCARI, E. M. H.; MELO, N. T. Guia para identificação: fungos, actinomicetos, algas de interesse médico. São Paulo: Savier, 1998. 445 p.

MAGALHÃES, M. J.; SILVA, N.; MARQUES JUNIOR, A. P. Otite externa em cães atendidos no Hospital Veterinário da Universidade Federal de Minas Gerais: etiologia, frequência e sensibilidade antibiótica. Arquivo Brasileiro de Medicina Veterinária e Zootecnia, Belo Horizonte, v. 37, p. 333-341, 1985. 
MATSUDA, H.; TOJO, M.; FUKUI, K.; IMORI, T.; BABA, E. The aerobic bacterial flora of the middle and external ears in normal dogs. Journal of Small Animal Practice, Londres, v. 25, p. 269-274, 1984.

NATIONAL COMMITTEE FOR CLINICAL LABORATORY STANDARDS - NCCLS. Performance standards for antimicrobial disk susceptibility test for bacteria isolated from animals. Wayne: Clinical Laboratory Standards Institute, n. 17, p. 1-34, 2006.

NELSON, W. R.; COUTO, G. C. Medicina interna de pequenos animais. 4. ed. Rio de Janeiro: Elsevier, 2010. $1674 \mathrm{p}$.

OLIVEIRA, L. C.; BRILHANTE, R. S. N.; CUNHA, A. M. S.; CARVALHO, C. B. M. Perfil de isolamento microbiano em cães com otite média e externa associados. Arquivo Brasileiro de Medicina Veterinaria e Zootecnia, Belo Horizonte, v. 58, n. 6, p. 1009-1017, 2006.

QUINN, P. J.; CARTER, M. E.; MARKEY, B.; CARTER, G. R. Clinical Veterinary Microbiology, Londres: Wolfe/ Mosby, 1994. 647 p.

QUINN, P. J.; DONELLY, W. J. C.; CARTER, M. E.; MARKEY, B. K. Microbiologia veterinária e doenças infecciosas. Porto Alegre: Artmed, 2005. 512 p.
RYCROFT, A. K.; SABEN, H. S. A clinical study of otitis externa in the dog. Canadian Veterinary Journal, Ottawa, v. 18, n. 3, p. 64-70, 1977.

SHIMIZU, A; WALITA, Y.; NAGASE, S.; OKABE, M.; KOJI, T.; HAYASHI, T.; NAGASE N.; SASAKI A.; KAWANO J.; YAMASHITA K.; TAKAGI, M. Antimicrobial susceptibility of Staphylococcus intermedius isolated from healthy and diseased dogs. Journal of Veterinary Medical Science, Toquio, v. 63, n. 3, p. 357-360, 2001.

SLATTER, D. Manual de cirurgia de pequenos animais. 3. ed. Barueri: Manole, 2007. 2713 p. 2 v.

SOUZA, A. V. G.; SALERNO, T.; SIQUEIRA, A. K.; RIBEIRO, M. G.; PAES, A. C.; LISTONI, F. J. P. Perfil de sensibilidade microbiana em 135 linhagens de Pseudomonas aeruginosa isoladas de cães com otite. In: REUNIÃO ANUAL DO INSTITUTO BIOLÓGICO DE SÃO PAULO, 19., 2006, São Paulo. Anais... São Paulo:[s.n], 2006. CD-ROM.

TAVARES, W. Manual de antibióticos e quimioterápicos antinfecciosos. 3. ed. São Paulo: Atheneu, 2011. 1216 p. 